\title{
Professor Anthony Clare: an appreciation of his contribution to psychiatry
}

Ir J Psych Med 2007; 24(4): 127-128

On 29th October 2007, Irish Psychiatry unexpectedly lost its brightest star. For over $\mathbf{3 0}$ years, Professor Anthony Clare, psychiatrist, author and broadcaster was the voice and face of psychiatry in these Islands. Many people will remember Tony Clare as a media personality who demystified and destigmatised psychiatry and made it more understandable to the general public. However, he was a man with many gifts, not least his immense talents as clinician, communicator, educator and agitator for a change in attitude by psychiatry and towards psychiatry.

Tony acknowledged that he was drawn into psychiatry in 1968 by Professor Norman Moore, Medical Director of St. Patrick's Hospital. Tony was also influenced by Professor Peter Beckett, Chair of Psychiatry at Trinity College Dublin at the time. After two years as registrar at St. Patrick's Hospital, he left Ireland to further his career at the Institute of Psychiatry. On arrival at the Maudsley Hospital in London in 1970, he quickly became involved in the burning political issue of the time for postgraduate trainees in psychiatry: the implications for training brought about by the evolution of the Royal College of Psychiatrists from the Royal Medico-Psychological Association. He was soon the spokesperson for the trainee group, and he presented its case masterfully at a pivotal meeting that included all the senior dignitaries of the emerging College. The trainees achieved their aim of persuading the new College to lay emphasis on good training for its potential members rather than relying exclusively for election to membership on the traditional Royal College style, stand-alone examination. The Royal College of Psychiatrists was thus at the forefront of medical disciplines in bringing about planned postgraduate training in the U.K. and Ireland. Tony Clare was at the vanguard of this movement in the 1970 ss and it is one of his enduring contributions to the field of psychiatry.

After completing registrar and senior registrar training at the Institute in 1975, Tony became a research worker in the General Practice Unit with Professor Michael Shepherd, one of the intellectual powers of the Institute at the time. This was a very productive academic period, when he published a range of high impact scientific papers and was awarded an MPhil and MD for this work.

At this time Tony was writing his most influential book 'Psychiatry in Dissent', which was published in 1976. In this book he brilliantly adapted for a wide readership up-to-date thinking on such controversial topics as schizophrenia, ECT, psychosurgery, concepts of mental illness, and responsibility and compulsion in treatment. 'Psychiatry in Dissent' was written at a turbulent time in psychiatry, when there was polarisation between the psychiatry establishment and the anti-psychiatry movement. Tony reached an inclusive compromise in his book, masterfully bridging the biomedical and psychosocial divide of mental illness models. He thus began his unique contributions to the field: increasing the awareness and understanding of psychiatry and mental illness and most importantly, reducing fears of psychiatric assessment and treatment.

In a review of 'Psychiatry in Dissent' in the British Medical Journa/ at the time, WH Trethowan spoke of the propensity of the young Tony Clare to ensure that the views of psychiatrists in training were made known to their teachers' and hinted at Tony's inclination to rattle establishment cages, particularly about training issues. In the final chapter of 'Dissent', Tony took issue with the College and pointed out how foreign born trainees were at a disadvantage in taking the membership due to the lack of adequate postgraduate facilities afforded to this group.

After a very successful career at the Institute, Tony became Chair of Psychological Medicine at St. Bartholomew's Hospital, Medical School London from 1983-1988. As Professor of Psychological Medicine, he transformed a traditional medical curriculum with psychiatry at the periphery into a curriculum in which psychiatry was at the centre. As a result of his influence, the number of interns opting for a career in psychiatry at Bart's increased significantly during his time there. Every Thursday evening at 5 o'clock, he chaired a case conference where he himself interviewed the patient. These case conferences were attended by large numbers of staff and the patients presented were usually complex or problematic cases. The manner in which Tony interviewed the patients was mesmerising. Within a matter of minutes, the patient would be oblivious to the large audience and would open up to him in a manner they would never have previously done. His warmth and sincerity with each patient was palpable. There was never a series of case conferences like these before in London and probably none since then.

There was one memorable event in 1987 , on a Thursday evening, when Tony invited members from various voluntary organisations involved in mental health, to a meeting at Bart's to discuss psychiatric services. Over 100 people attended the meeting and many arrived with a rather hostile attitude and a highly negative view of psychiatry. Many of the participants were overtly anti-psychiatry and viewed psychiatrist with enormous suspicion. The meeting began with a decided degree of tension in the air. Within a short period, however, Tony had imposed his calming influence on events. By the end of the meeting, he had achieved what probably no one else could have: a meeting of minds between psychiatrists and some of the most fervent anti-psychiatrists in the East end of London.

In 1989, Tony returned to his native Dublin to take up the position of Medical Director at St. Patrick's Hospital and Clinical Professor of Psychiatry at Trinity College Dublin. He 
completed two terms as Medical Director at St. Patrick's Hospital between 1989 and 2000. As Medical Director, he was instrumental in the expansion of the Dublin University Training Scheme to include the Kildare and St. Loman's services. Although Medical Director of the largest private hospital in the country, Tony believed that the training experiences of young psychiatrists must be expanded beyond the hospital setting and embrace community, outreach and rehabilitation aspects. Such was his love and interest in the scheme and the issue of training that he remained active in the selection of trainees for the scheme up to the time of his death.

His medical directorship at St. Patrick's Hospital was noted for hosting major annual scientific meetings on the occasion of Founder's day, to mark the death of Jonathan Swift, the founder of St. Patrick's Hospital. Many of the great names of psychiatry came to speak at his invitation, raising the profile of psychiatry in Ireland and exposing young trainees to world renowned experts.

Throughout his tenure at St. Patrick's, Tony Clare energetically mentored, supported and encouraged the training and research careers of many young psychiatrists. Most of these psychiatrists have since returned to these shores to take up leadership roles in Irish psychiatry and openly acknowledge his enormous contribution to their professional and academic success.

Tony was an active member of the Irish Psychiatric Training Committee from the time he returned to Ireland. In latter years he was particularly influential in national training issues, in his work as a member of the Medical Education and Training Committee of the National Taskforce on Medical Staffing.

On his retirement from the Medical Directorship of St Patrick's he was appointed Adjunct Professor in the Department of Psychiatry, Trinity College Dublin, in recognition of his achievements in psychiatry and his many contributions to the Department. In 2001, Tony moved to work fulltime as consultant psychiatrist in St. Edmunsbury. There, he immersed himself in clinical practice, applying his eclectic model of mental illness as he treated patients within their biological, social and psychological context and in concert with other professional disciplines. It was in a sense, back to the future for him and the days of 'Dissent'.

Tony continued to maintain his interest in training issues and the education of trainees. In 2002 he was involved in the College initiative on trainee safety and did the narrative for 'Safety in Psychiatry: The Mind Eye', the aim of which was to raise awareness amongst trainees of safety in the work environment. He was a constant attendee at the case conferences in St. Patrick's Hospital up to the week before his death, always primed to ask the difficult questions, and always ready to offer solutions and advice.

Throughout his professional career, Tony demonstrated an extraordinary ability to provide visionary analysis of issues in psychiatry that has stood the test of time. His emphasis, over a professional life time on the importance of training in psychi- atry reverberates currently given the challenges that we face in Ireland and elsewhere in securing the future of post graduate training in psychiatry. He was also mindful in later years of the potential dangers of the erosion of the more eclectic and holistic model of mental illness by the narrow focus on biology and molecules, which now, once again, over 30 years after 'Dissent', could open the door to a rear guard action by a 'nouveau anti-psychiatry' movement.

It is difficult to capture the magnitude of the influence that Tony Clare had on the field of psychiatry and on his peers, colleagues and trainees in both Ireland and the UK. His influence will continue to have an impact that will last throughout and beyond our professional life times. His broader legacy relates to his success in decreasing the stigma of psychiatry in the eyes of the general public and the medical profession as a whole, while at the same time encouraging the development of a strong positive identity within psychiatry itself. There is a sense of pride and deep respect in having known him, worked with him, trained under him or seen him in action: challenging, questioning, comforting.

With Tony Clare, there was never a neutral position. Neutral did not appear in his lexicon or vocabulary. In his life and in his writing, he was passionate about issues and he continually asked questions: about psychiatry, medicine society, science, research and evidence, but most of all, he posed the hardest questions of himself. When asked what it is that makes a successful doctor, he once wrote: "Knowledge, lateral thinking, communications skills and, the most basic of all, a sixth sense that all is not well with your patient. All of these contribute to (your) success. They are, of course, difficult to teach - learn them from your peers as an apprentice would learn from a master. They will make all the difference to (your) success as a doctor."

Tony possessed that sixth sense that makes a great psychiatrist and many trainees in Ireland and the UK were privileged and fortunate enough to learn from a true master of his generation.

To mark Tony Clare's professional life and to reflect his great interest and tremendous contribution to the area of training in psychiatry, the Irish Journal of Psychological Medicine, with the agreement of the IPTC has published his 2005 reflections on the future of training in psychiatry in Ireland in this issue. Just as 'Psychiatry in Dissent' remains relevant and current today over 30 years after its publication, so too are his insightful and incisive comments on the direction that post graduate training in psychiatry In Ireland must take and the challenges that we face in the years ahead.

He said prophetically in his closing remarks on that day in May 2005 that he was not going to be around to fight the battle into the future but that the battle must be fought. While we do not have Tony to lead us any longer, his legacy will be that he has shown us the way.

$\mathrm{He}$ is a tremendous loss to the field of psychiatry, but most of all to his loving wife Jane and their family.

- BAL, MGTW \& TGD 